\title{
An electromyographic investigation of motor conflict'
}

\author{
M. S. HOSHIKO AND H. L. GRANDSTAFF 2 \\ SOUTHERN ILLINOIS UNIVERSITY, CARBONDALE, ILLINOIS
}

$M A P$ recordings, reaction times, response times, and the written modes of resolution were obtained during nonconflict conditions and four types of conflict conditions. These data were the results of normal male $S$ s responding to stimuli during the approach-avoidance and double approach-avoidance responses. Reaction times, response times, and the written modes of resolution were consistent with data obtained by previous investigators.

Four different types of conflict situations have been hypothesized. Lewin (1935) originally suggested the first three types of conflict, and Hovland \& Sears (1938) described a fourth. All of them have been experimentally elaborated on by Dollard \& Miller (1950) and others. The types of conflict are: approachapproach, avoldance-avoldance, approach-avoidance, and double approach-avoldance.

Conflict situations frequently increase reaction or choice time according to many studies reported, among them ones by Baker (1942), Atthowe (1960), and Berlyne (1967). Malmo, Shagrass, \& Davis (1951) reported that psychoneurotic and psychotic patients responded to stress situations with a greater degree of muscular cension in the forearm and neck than did normal controls. Davis \& Barza(1952) suggest that flexor-extensor opposition in muscles of the forearm was more likely a feature of motor conflict than of conflict-free overt reactions. Sheehan (1957) suggests that one possible theory for the cause of stuttering is that of approachavoidance conflict. He reported that when approach responses were strengthened, fluency increased; when avoidance responses were strengthened, stuttering increased.

This study was designed to investigate the possible muscular manifestations of the four types of conflict situations. Measures were made of muscle activities at two sites, reaction time, response time, and written mode of resolution, during responses to tasks on a conflict board which were presented as conflict and nonconflict trials.

Method

Ss were forty right-handed male undergraduate students at Southern mlinois University, having no abnormalities of the right arm.

Muscular action potential (MAP) was recorded on an eight-channel Medcraft electromyograph. The conflict apparatus was patterned after that used by Hovland and Sears. The lights were controlled from a switch box located outside the S's vision. When a light switch was turned on, an event mark was recorded by the electromyograph. Another mark also was recorded by the electromyograph when the switch was turned off.
There were $10 \mathrm{Ss}$ in each of four types of conflict. The Ss had electrodes attached to their right forearms at two sites, on the flexor carpl radialis and on the back of the hand at the second dorsal interossel. The exact placement of electrodes was determined by a pilot study which suggested the muscle sites producing the greatest amount of action potential when the arm was directed toward either corner of the cunflict board and when the pencil was squeezed. The Ss were instructed as to the task, according to the type of conflict involved. Recordings were made of Trials 1, 5, 10, 15, and 20, and the conflict trial, Trial 21. The $S$ was seated comfortably in a chair in front of the conflict board, with his stylus in the center groove. When the light came on, he was to move the stylus to the appropriate corner and say "finished" at the end of his response.

\section{Results and Discussion}

Results were analyzed by comparing the mean MAP of the conflict and nonconflict trials. Data for the five nonconflict trials were averaged together, as there were no significant differences between any of the trials. Differences were taken for mean MAP between conflict and nonconflict trials and the Wilcoxon matchedpaires signed-ranks test for differences applied to the differences in $\mu \mathrm{V}$. Reaction time was judged to be the lapse of time between onset of the stimulus light and the first MAP from the forearm or hand. Total response time was judged to be the time between the onset of the stimulus light and when the $S$ said the word "finished." Reaction time and response time of nonconflict and conflict trials were compared by using the $t$ for paired observations. The written modes of resolution were examined in the same way used by Hovland and Sears.

No significant differences of mean MAP for either muscle site for approach-approach and avoidanceavoidance conditions were found. However, for the approach-avoidance condition, 7 out of $10 \mathrm{Ss}$ showed more MAP during a nonconflict response than during a conflict response. This was significant at the $5 \%$ level for both muscle sites. In the double approach-avoldance condition, the results for the second dorsal interossel showed a significantly smaller mean MAP in the conflict condition.

The mean reaction times for the single, double, compromise, and blocking modes of written resolution were .26, .30, .45, and $4.08 \mathrm{sec}$, respectively. The mean reaction times for the approach-approach, avoldance-avoidance, approach-avoidance, and double approach-avoidance conflicts were $.18,3.18, .58$, and .56 
sec, respectively. The average reaction times for the nonconflict Trials $1,5,10,15$, and 20 were .36, .32, $.30, .30$, and $.30 \mathrm{sec}$, respectively. These results indicate: (1) increased reaction times for the blocking mode of resolution; (2) increased reaction time for the avoidance-avoidance conflict; (3) avoidance-avoidance, approach-avoidance, and double approach-avoidance mean reaction times were greater than nonconflict conditions; (4) approach-approach conflict mean reaction times were less than nonconflict conditions.

The mean total response times for the approachapproach, avoidance-avoidance, approach-avoidance, and double approach-avoidance conflicts were 4.08 , $35.03,6.01$, and $19.01 \mathrm{sec}$, respectively. The nonconflict Trials $1,5,10,15$, and 20 had total response times of $1.25,1.06, .98, .90$, and $.96 \mathrm{sec}$, respectively. These results indicated that the avoidance-avoidance conflict took the greatest amount of time to resolve. All four types of conflict had greater amounts of response time than any of the nonconflict conditions (significant at the 5\% level). The single, double, compromise, and blocking modes of written resolution had mean response times of $17.06,15.11,5.06$, and $21.15 \mathrm{sec}$, respectively. These results indicate that blocking produced the longest mean response time while compromise produced the shortest. These differences were not significant.

Analysis of the records suggested that the identifiable kinds of written modes of resolution to the four types of conflict were the same as those found by Hovland and Sears. The results indicated that $60 \%$ of the $\mathrm{Ss}$ in the avoidance-avoidance condition blocked, agreeing with Hovland and Sears' results. The approach-avoidance condition was the only one to produce a compromise form of resolution.

These results show some fairly definite trends in muscle activity and reaction times in conflict situa- tions. Standard deviations were large, so that despite fairly substantial differences between conditions, statistical evaluations were frequently not significant. Where there was a significant difference between conflict and nonconflict trials, the conflict trials gave a significantly smaller mean MAP. The avoidance-avoidance conflict situation gave a blocking mode of resolution, or no responding at all, while the approach-avoldance condition gave a compromise as a frequent mode of resolution.

\section{References}

ATTHOWE, J. M. Types of conflict and their resolution: A reinterpretation. J. exp. Psychol, 1960, 59, 1-9.

BAKER, R. G. An experimental study of the resolution of conflict by children: Time elapsing and vicarious trial and error behavior occurring. In G. McNemar and M. A. Merrill (Eds.), Studies in personality. New York: McGraw-Hill, 1942.

BERLYNE, D. E. A theory of human curiosity. Brit. J. Psychol, 1954, 45, $180-191$.

DAVIS, J. F., \& BARZA, S. Total hysterical deafness: An experimental case study. J. Pers, 1952, 21, 188-204.

DOLlARD, J., \& MILLER, N. Personality and psychotherapy. New York: McGraw-Hill, 1950.

HOVLAND, C. I., \& SEARS, R. R. Experiments on motor conflict: I. Types of conflict and their modes of resolution. $J$. exp. Psychol, 1938, 23, 447-493.

LEWIN, K. A dynamic theory of personality. New York: McGraw-Hill, 1935.

MALMO, R. B., SHAGASS, C., \& DAVIS, J. F. Electromyographic studies of muscular tension in psychiatric patients under stress. J. clin. exp. Psychopathol, 1951, 12, 45-66.

SHEEHAN, J. G. Stuttering as conflict: 1 . Comparison of therapy techniques involving approach and avoidance. J. Speech hear. Disord. 1957, 22, 714-723.

\section{Notes}

1. This research was supported in part by Public Health Service Grant No. N. B.-03484-04, from the National Institute of Neurological Diseases and Blindness awarded to M. Hoshiko and it represents an M.S. thesis by $\mathrm{H}$. Grandstaff and directed by $M$. Hoshiko.

2. Now at Miami University, Oxford, Ohio. 